\title{
Ideology, policy and implementation: Comparative perspectives from two African universities
}

\author{
Charlyn Dyers \\ Department of Linguistics, University of the Western Cape, South Africa \\ E-mail: cdyers@uwc.ac.za \\ Jane-Francis Abongdia \\ School of General and Continuing Education (SGCE), University of Fort Hare, South Africa \\ E-mail: jabongdia@ufh.ac.za
}

\begin{abstract}
This paper provides an exposition and interpretation of the language policies of two African universities, namely the University of Yaoundé 1 in Cameroon and the University of the Western Cape in South Africa. It does so against the background of the socio-historical and political factors that led to the creation of both universities and their respective language policies. The authors' main argument is that well-intended, liberal language policies are often impossible to implement as a result of the powerful influence of political and linguistic ideologies shaped, on the one hand, by many years of colonisation and the resulting marginalisation of the indigenous languages in both countries, and, on the other, by ideologies of nation-building and assimilation in the post-colonial era. The paper also attempts to find greater conceptual clarity between the concepts of 'language attitudes' and 'language ideologies'.
\end{abstract}

Keywords: language ideologies, language attitudes, language policy, University of the Western Cape, University of Yaoundé 1

\section{Introduction}

Against the socio-historical and political backgrounds of Cameroon and South Africa, this paper provides an exposition and interpretation of the language policies of two major universities, namely the University of Yaoundé 1 in Cameroon and the University of the Western Cape (UWC) in South Africa. The core theoretical issue under investigation here is how both political as well as particular language ideologies play a major role in influencing and shaping national and institutional language policies and their implementation. The two universities were specifically chosen because of the role English plays at both institutions. Another factor they have in common is that their respective language policies result from particular political ideologies which imposed bi- or multilingual language policies at national, provincial and university levels. However, in line with the findings of other researchers in this 
field (e.g. Bamgbose 2000, Alidou 2007, Hill 2010, Neethling 2010), actual language practices at these universities do not reflect the aims of these policies. In its analysis of the dominant language ideologies at play in both settings, the paper also hopes to achieve greater conceptual clarity between the concepts of 'language attitudes' and 'language ideologies'.

The paper commences with a brief historical overview of both countries and the two universities in question. It then provides the theoretical and conceptual framework as well as the methodology used for the study on which this paper is based. The findings of the study are then linked to particular ideologies which seem to work against the aims of the language policies of the two universities while, at the same time, revealing the contradictions and contestations present not just in policy implementation, but also in the responses and narratives of different respondents. The paper is based on the $\mathrm{PhD}$ thesis of the second author (Abongdia 2013) which was supervised by the first author.

\section{A brief overview of the histories of Cameroon and South Africa and the two universities}

It is obviously difficult to capture the histories of both countries as well as the two universities in question in great detail in a single paper. Nevertheless, each country is marked by a number of distinctive historical periods which have influenced the development of their respective language policies. These historical periods will briefly be described in the subsequent sections.

\subsection{Cameroon}

The modern state of Cameroon developed as a result of the following key periods:

- A pre-colonial era in which Cameroon was divided into kingdoms and chiefdoms using many different indigenous languages like Basaa, Duala, Bulu, Ewondo and Mungaka (Mbuagbaw 2000:135, cited in Echu 2004).

- The period of German colonisation (1884-1917) when the colonial government encouraged the use of the German language (Echu 1999). However, Christian missionaries continued with the use of the local languages in education and evangelism until these schools were forced to close down in 1889 and German was made the only medium of instruction (MOI) in schools (Echu 2003).

- The Franco-British period following the defeat of Germany in World War I in 1918, when the country was divided into separate Francophone and Anglophone territories. France governed four-fifths of the territory, and Britain only one-fifth, which means that French was far more widely used than English (Fonlon 1969).

- Reunification in 1961 leading to the birth of the Federal Republic of Cameroon, with the two dominant colonial languages adopted as the official languages of the new state, and the encouragement of bilingualism in French and English to promote national unity. French became the lingua franca in the Francophone territories of Cameroon while Cameroonian Pidgin English (CPE) served the same purpose in the Anglophone ones. The two territories also used different systems of education - an English medium and a French medium subsystem. While there may not have been any real sociolinguistic conflict between the Anglophone and Francophone populations, each of them has developed distinct identity boundaries that exclude the other (Mforteh 2006). 
- Despite a lack of any clear policy on the indigenous languages, the 1998 and 2002 constitutions promoted and encouraged the use of mother-tongues in schools. In addition, Tamanji (2008:151-152) reports that teaching of the indigenous languages is now taking place in Cameroon at university level. The University of Yaoundé 1 now has a Department of Linguistics and African Languages that seeks to promote the teaching and use of some of these languages.

\subsubsection{The University of Yaoundé 1}

The University of Yaoundé 1 is the oldest state-owned university in Cameroon. It was founded in 1962 by presidential decree, and with the help of the French government, as the Federal University of Yaoundé. Following a growth in student numbers, the university reforms of 1993 split the university into two different universities: the University of Yaounde 1 and the University of Yaoundé 2. These two universities were established to meet the standards and quality of European universities (Nkwi and Socpa 2007:67). In line with the state language policy, both universities officially follow the bilingual language policy which is supposed to cater for both Anglophone and Francophone students and staff.

\subsection{South Africa}

Like Cameroon, South Africa has also been colonised by different European powers which led to the dominance of particular languages in official domains. What follows are the key periods in the development of South Africa:

- A pre-colonial era during which three dominant groups could be found in the territory: its original inhabitants, the Khoi and San people who have lived here for millennia, and the Bantu people who migrated to this region from the Great Lakes area around the $12^{\text {th }}$ century. According to Beukes (2003), a large number of the South African population belongs to two major language groups: Nguni (which includes the languages isiXhosa, isiZulu, siSwati and isiNdebele) and Sotho-Tswana. Black African rulers founded powerful kingdoms and nations by incorporating chiefdoms leading to the emergence of the Zulu, Xhosa, Pedi, Venda, Swazi, Sotho, Tswana, and Tsonga nations.

- The arrival of Europeans (Portuguese, Dutch, French, German, and British) in the $16^{\text {th }}$ and $17^{\text {th }}$ centuries as well as Asians (Malay, Indonesian, and Indian) brought in as slaves, political prisoners and indentured labourers from the $18^{\text {th }}$ century (Beukes 2003).

- The period of Dutch settlement and rule (1652-1795 and 1803-1806 respectively), leaving South Africa with its own local variety of Dutch which was to develop into the hybrid contact language which is known today as Afrikaans (Roberge 1995:73).

- The British colonisation after the Congress of Vienna (1814-1815), which made English the language of the law courts and education (Beukes 2003).

- The Great Trek into the interior of South Africa by the Boers, sparked by the freedom of the slaves in 1835, which led to further colonisation, several wars with the indigenous nations - particularly the Xhosa and powerful Zulus - as well as the Anglo-Boer War which finally led to the Union of South Africa in 1910. Naturally, all these important historical events also aided the spread of the Dutch and English languages amongst speakers of other languages. English and Afrikaans were granted equal status in the Act of Union and Afrikaans began to be taught in schools from 1925. 
- The rule of the Afrikaner Nationalist Party from 1949 to 1993 (also known as the "apartheid era"), accompanied by the enforced use of Afrikaans, often to the detriment of English. Despite this, English continued to dominate in education and finance, while about $70 \%$ of South Africans spoke one or more of the South African indigenous languages (Kaschula and Anthonissen 1995). The indigenous languages were continuously kept separate from one another through lexical and other corpus planning manoeuvres as the apartheid government pretended to be developing these languages through separate language boards (Alexander 1992, Heugh 2003). Bantu Education was imposed on the black people and the leaders of the liberation movement supported English as the language of liberation.

- The advent of democracy in 1994, when 11 languages, including English and Afrikaans, were selected as official languages. English now functions as the main lingua franca among speakers of different languages as it is the preferred second language in school education and is widely used in the media (Beukes 2003). Yet many South Africans, as a result of the dysfunctional education system which continues to plague the country post-liberation, do not have a good command of the high status languages (English and Afrikaans) to enable them to compete for well-paid jobs.

\subsubsection{The University of the Western Cape}

UWC was established in 1959 during the apartheid era by an Act of Parliament as an ethnic college for "coloured" students. From 1982 onwards, it was transformed to become an internationally recognised university with a reputation of excellence in teaching and research. It was opened as a bilingual Afrikaans- and English-language university college (mainly aimed at training high school teachers) in 1960, raised to the status of a full university in 1970 and gained its autonomy in 1983 through the University of the Western Cape Act. It was after this period that English became the dominant language of learning and teaching at the university. Due to its contribution to the liberation struggle against the apartheid regime, UWC is aware of a distinctive academic role in helping to build an equitable dynamic society and has quite a diverse student and staff population. In line with state and provincial language policies, the university finalised its multilingual language policy in 2003; this policy acknowledges isiXhosa as one of the three major languages at the university.

\section{Theoretical and conceptual framework}

Within the context of post-colonialism, the late-modern era and globalisation, this paper interrogates the notions of 'ideologies' (with specific focus on language ideologies), 'language attitudes' (with specific regard to language status) and 'language policy'. Blackledge (2005:32) contends that language ideologies "are positioned in, and subject to, their social, political and historical contexts" and are inscribed in many "chains of discourse" (Blackledge 2005:209). Language policy is one of these discursive chains and cannot be detached from the politics and history of either the country or institution which draws up such policies.

Given their centrality to this paper, the writers commence with an examination of some of the definitions of the concepts of 'ideologies' and 'language ideologies'. A common dictionary definition of "ideology" is "a set of doctrines or beliefs that form the basis of a political, economic or other system" (Free Online Dictionary). However, it is important to acknowledge 
that language policies, and even languages, may be steeped in ideologies that are not primarily about language, but rather about issues like nation-building or group identity.

Irvine (1989:255) defines ideology as "the cultural system of ideas about social and linguistic relationships, together with the loading of moral and political interests". This definition emphasises the "moral and political interests" that underpin societal ideologies, and shows that ideologies cannot exist outside of the power relationships in any society. Myers-Scotton (2006:135) defines ideologies as the "patterns of beliefs and practice, which make some existing arrangements almost always seem 'natural' because they (or their forebears) are the ones who put these arrangements in place". By "they", Myers-Scotton clearly means the dominant groups in a society who have, over lengthy periods of time, established the existing arrangements in that society so that everyone, even the dominated groups, comes to see such arrangements as normal and natural. These naturalised arrangements are further emphasised in Fairclough's (2003:9) definition of ideologies as

representations of aspects of the world which contribute to establishing and maintaining relations of power, domination and exploitation. They may be enacted in ways of interaction (and therefore in genres) and inculcated in ways of being identities (and therefore styles).

Fairclough adds that if ideologies are primary representations of those aspects that help to establish and maintain power in societies, they can nevertheless also be "enacted" in ways of acting socially - what people actually do and what people actually say - and "inculcated" in the identities of social agents. This is a very important point, and signals that the ideologies inculcated by different social agents (e.g. politicians, policy makers, educators and parents) can have an influence on the shaping of national and institutional policies like language policies and the success or failure of the implementation of such policies.

It is the contention of this paper that ideologies about language can underpin, determine and affect many other domains of human activity such as the creation of language policies. However, they are themselves not policies or practices, but rather ideas or beliefs about language. This can be seen in Irvine and Gal's (2000:35) definition of language ideologies as

$[\ldots]$ the ideas with which participants and observers frame their understanding of linguistic varieties and map those understandings onto people, events and activities that were significant to them. [...] Linguistic ideologies are held not only by the immediate participants in a local sociolinguistic system. They are also held by other observers, such as the linguists and ethnographers who have mapped the boundaries of languages and peoples and provided descriptive accounts of them.

In this definition, Irvine and Gal emphasise how ordinary people understand the role of different language varieties and link this understanding to their perceptions of, and responses to, the speakers of such varieties. In addition, the definition also shows how people perceive and interpret the role of language in major events that affect their lives (e.g. political speeches, dealing with government departments and other state institutions like hospitals) as well as the ways in which particular language varieties impact on their daily activities (e.g. at work, in schools and universities and places of worship). 
For Myers-Scotton (2006:110), an additional focus of language ideologies is on "[ ...] how real or fabricated differences in languages (their histories or who is most associated with speaking one as opposed to another) are exploited in the political arena". A very clear example of how politics exploits supposed differences in languages can be found in South Africa, where the Nguni languages (isiZulu and isiXhosa) have developed into separate languages not because of any major fundamental linguistic differences, but because of political and historical developments.

Ideologies about language are of course not about language alone, but reflect issues of social and personal identity (which includes social status) and are reflected in actual linguistic practice - how people talk, what they say about languages, the language choices they make for themselves and their children, and what they regard as essential languages for both survival and advancement in terms of employment opportunities and social standing. These issues of social and personal identity are reflected in Weber and Horner's (2012:16) definition of language ideology as the "cultural system of ideas and feelings, norms and values, which inform the way people think about language". Of relevance to this paper are the five major language ideologies listed by Weber and Horner (2012:16-20):

- The language hierarchy ideology influences the division and labelling of languages. Languages can be categorised as "languages", "dialects", "patois", etc. with "languages" enjoying the highest status. Some languages also enjoy a higher status than others when they are labelled as "national languages" or "official languages";

- The standard-language ideology is based on the belief that languages are internally homogenous, bounded entities, with a certain variety chosen for standardisation simply because of socio-political movements, and definitely not because of any inherent superiority of these varieties over others;

- The ideology of language purism influences stipulations on what constitutes "good" and "bad" language usage and often appears in times of rapid social change;

- The one-nation one-language ideology is the belief that language is equal to territory and national identity; and

- The mother-tongue ideology is the belief that speakers only have one mother-tongue.

Weber and Horner (2012:20) conclude that the fear of linguistic heterogeneity and ideologies of purism are not just ideas and attitudes about language but are eventually translated into practices and policies that can lead to social consequences for the entire community.

Although Pavlenko (2004) argues that language ideologies are gradually replacing language attitudes as a field of research, many scholars still draw on the concept of 'language attitudes'. It is therefore necessary to examine the often taut areas of overlap and differences between the two concepts. According to Dyers and Abongdia (2010:120-123), studies in language ideologies and language attitudes overlap in two areas: firstly, both deal with the issue of status and how this affects patterns of language shift and maintenance in societies. Secondly, according to Kroskrity (2000), there is a multiplicity of language ideologies which effectively captures social divisions within socio-cultural groups. In the same way, language attitudes also tend to differ depending on factors like age, gender, social class and level of education.

Dyers and Abongdia (2010:123) argue that language attitudes and language ideologies differ fundamentally in only one main area: "Ideologies are constructed in the interest of a specific 
social or cultural group: i.e. they are rooted in the socio-economic power and vested interests of dominant groups". However, it can also be seen how subordinate groups, on whom such ideologies are imposed, gradually start to accept these ideologies as "normal" patterns of behaviour. The use of English as MOI and also as an official language is a good example in the case of South Africa while English and French occupy the same position in Cameroon. However, it is important to note that subordinate groups also have their own ideologies and may develop counter-discourses to the ideologies of the powerful. An example of how ideologies are espoused or contested can be seen in the Soweto uprisings of 1976 in South Africa, when school children rose up against the imposition of Afrikaans (seen as "the language of the oppressor") as the MOI for $50 \%$ of their high school subjects. These learners were objecting to an educational policy and related practices prescribed on the basis of a particularly divisive ideology.

How do the above definitions and discussions relate to the issues of language planning, policy and implementation? According to Baldauf and Kaplan (2006:8), language policy and planning occur in an environment circumscribed by language ideologies arising from "historical and material situations; from socio-political and historical frameworks of power caused by discrimination and nation building". They contend that language in education is one of the major areas where the language policy of a country can be observed, and argue that there is a discrepancy between the language policies put in place and actual practices carried out in reality. Instead, they hold that most policies are "diametrically opposed to reality" (Baldauf and Kaplan 2006:9), and are driven by political rather than linguistic forces. Spolsky and Shohamy (2000:3) concur with this line of argument and define language policy as "an effort by someone with or claiming authority to change the language practice (or ideology) of someone else". The central role of government can be seen in the following definition of language policy by Crawford (1988:1):

1. What government does officially - through legislation, court decisions, executive action or other means - to (a) determine how languages are used in public contexts, (b) cultivate language skills needed to meet national priorities, or (c) establish the rights of individuals or groups to learn, use, and maintain languages.

2. Government regulation of its own language use, including steps to facilitate clear communication, train and recruit personnel, guarantee due process, foster political participation, and provide access to public services, proceedings and documents.

In other words, a language policy is a political document and is dependent on a government steeped in particular ideologies for its effective implementation.

It is also important to include here the distinction between overt and covert language policies (Schiffman 1996, Shohamy 2006). While overt language policies are either explicitly formulated and published documents or clearly understood verbal agreements, covert ones may emanate from particular ideologies and may actually work against overt policies in various settings. As Schiffman (1996:13) argues: 
The implicit and latent language policy is an integral part of the culture of the specific entity and is supported and transmitted by the culture, irrespective of the overt policy with regards to the various codes in question.

The relationship between power, ideology and language policy is further captured effectively by Cobarrubias (1983:63-66) who describes four key ideologies of language planning. These are ideologies of:

- linguistic assimilation - everyone should learn the state's dominant language/s, as in the case of English in the United States of America;

- linguistic pluralism - more than one language is recognised, as in the case of South Africa (11 official languages) and Cameroon (two official languages);

- vernacularisation - the revival and elaboration of an indigenous language which then becomes an official language, as in the case of Swahili in Tanzania; and

- internationalism - the use of a non-indigenous language for wider communication, business and international trade, as in the case of many African countries which rely on English, French or Portuguese for these functions.

Linguistic assimilation, if rigidly imposed, poses a threat to other languages and language varieties and can lead to the invisibilisation of such languages and even their speakers (Skuttnab-Kangas 2000). Linguistic pluralism, despite recognising more than one language, in no way ensures effective implementation of policies based on it. While vernacularisation may appeal to a sense of national and regional identity, it requires very firm and soundly implemented policies to ensure that it can give meaningful roles to such indigenous languages in the face of other competing international languages, as can be seen with the ideology of internationalism. Once major functions are performed in languages like English or French, the indigenous languages may always be restricted to more intimate domains or minor roles in areas like trade and education.

\section{Methodology}

The methodology required, in the first place, an analysis of the linguistic and political backgrounds of both countries and how these backgrounds related to the establishment of the two universities and their respective language policies, which have been summarised in section 2. Secondly, the language policies of the University of Yaoundé 1 and UWC had to be analysed within the context of the dominant ideologies in the two countries, in particular the ideologies of those who drafted the language policies of these universities. Thirdly, a cross-section of the populations (approximately 5\% of the total population) at both universities had to be sampled both quantitatively and qualitatively in order to determine the current ideological positions with regard to how effectively both policies were being implemented or even acknowledged.

\subsection{Data collection}

The data for this study were collected through the use of questionnaires completed by students and lecturers, as well as individual interviews conducted with purposefully selected lecturers, students and major stakeholders such as deans of faculties and administrators at both 
universities. In addition, a substantial amount of time was spent simply engaged in observation at these two research sites, and then recording these observations in daily field notes.

\subsubsection{Cameroon: Research population}

In terms of ethnicity, Cameroon is heterogeneous as the country has about 250 ethnic groups. The participants in this study belonged to the following groups: Beti (Ewondo, Bulu and Fang), Bamelike, Bamoum, Bassa, Douala, Tikari, Bakosi, Bayangi, Ngemba, Lamso and Mongakah. They largely spoke urban varieties of these different dialects. However, owing to the national language policy, all the respondents had been educated in either English or French at primary and secondary school and used CPE as a lingua franca.

In January 2010, 60 students and 15 lecturers in Cameroon completed the questionnaire, and 20 students and 10 lecturers were interviewed individually as well as in focus groups. The student respondents were third-year Linguistics students completing a module on Language Policy. Close observation of this module took place from December 2009 to January 2010, which was helped by the fact that the second author also assisted with lectures and consultations.

\subsubsection{South Africa: Research population}

The South African study was conducted with the same numbers of third-year BA students and lecturers at UWC, stakeholders and ordinary citizens. The study made use of 100 participants: 15 lecturers, 5 stakeholders, 60 students and 20 ordinary citizens. The students consisted of 34 coloureds (people of mixed ancestry, predominantly bilingual in English and Afrikaans), and 26 blacks ( 22 isiXhosa first-language speakers, two isiZulu- and two Setswana first-language speakers). A further breakdown of actual home-language (HL) use among the coloured students revealed that 26 indicated Afrikaans as their HL, four indicated English as their HL while a further four indicated both English and Afrikaans as their HLs. Naturally, the research population also spoke different varieties of these languages, particularly urban, blended varieties.

In 2010, 15 lecturers and 60 students at UWC completed the questionnaires. The student respondents were third-year Linguistics students completing a module called Multilingualism, which includes lectures on language planning and policy. A further 20 UWC students, 10 lecturers, two deans and three other stakeholders were interviewed. Lastly, informal discussions took place with cleaners, administration staff and security officers around the campus whenever they were available during their breaks. Their comments were taken down as part of the overall field notes.

\subsection{Data analysis}

The quantitative data were analysed statistically and the results were captured in percentages. The findings revealed:

- The demographic information of the respondents - personal background details in terms of age, gender, ethnicity; 
- Language use (in formal and informal situations) - information on language choice, preference and language education; and

- Attitudinal responses through the use of the Likert scale (Likert 1932) to particular closed questions on language choice and preference.

The qualitative data consisted of:

- An analysis of the language policies of both universities;

- Written responses to a set of open-ended questions which formed part of the main questionnaire;

- Transcribed individual and focus group interviews; and

- Field notes which contained observations as well as some participant responses and group discussions.

These four sources of qualitative data were analysed by using Thematic Content Analysis (TCA), Discourse Analysis (DA) and Critical Discourse Analysis (CDA). Hsieh and Shannon (2005:1278) define TCA as a research method for the subjective interpretation of the content of text data through the systematic classification process of coding and identifying themes or patterns. Qualitative content analysis examines language used in data collected for the purpose of classifying large amounts of text into an efficient number of categories that represent similar meanings. They see the goal of content analysis as being "to provide knowledge and understanding of the phenomenon under study" (Hseih and Shannon 2005:1278). TCA therefore gave us a number of themes according to which we could group the written and oral responses of our research population e.g. viewpoints on English, confusion regarding the existence of a language policy at the university, the role of the language policy in student success or failure, etc.

DA is defined by Cameron (2001:15) as a method for investigating the "social voices" available to the people whose talk is collected by analysts. According to her, many social researchers believe that people's understanding of the world is not merely expressed in their discourse; instead, it is actually shaped by the ways in which they use language that is available to them. In other words, reality is "discursively constructed" as it is made and remade as people talk about things using the "discourses" at their disposal (Cameron 2001:15). The "social voices" of the respondents in this study clearly showed how they constructed their experiences with the language policies and language realities at the two universities, and also provided access to their more personal language attitudes. In other words, once their experiences had been grouped according to TCA, their actual language use and the ways they used language to express their views could be examined more closely through DA.

The writers' understanding of CDA was largely informed by Wodak (2001) who argues that CDA is particularly concerned with the relations between language and power. The primary concern of any CDA endeavour may thus be to analyse obvious as well as tacit "structural relationships of dominance, discrimination, power and control as manifested in language" (Wodak 2001:2). Of particular interest here was to see what the discourses used by the respondents in the study signalled regarding positions of power they may have been in at the time of the research or reactions to existing power structures at both universities, with particular reference to tacit or explicit language policies. In line with studies by Besemeres (2006) and Dewaele (2006), such discourses were frequently signalled in the data by particular lexical 
items with strong emotional content e.g. this English, my Xhosa, the Francophones, the Anglophones, etc.

In addition, the respondents' tone of voice in the interviews was carefully noted as well as the manner in which the information was transmitted e.g. passively, happily, angrily or passionately. To ensure that the emotions were well captured, the second author personally transcribed the interviews in order to capture the facial expressions, gestures and body language of the respondents.

\section{Results}

\subsection{An exposition and interpretation of the language policies of the two universities}

In analysing the different language policies of the two universities, it was noted whose interests are served by these policies as well as what these policies seek to promote and/or deny within the social, political and economic structures of both countries. In other words, both the overt and covert policies (Schiffman 1996, Shohamy 2006) were examined for areas of agreement and contradiction, and their effects on the populations they are intended to serve.

\subsubsection{The University of Yaoundé 1}

Like Cameroon itself, the university has no formally written language policy. However, policies do not have to be in written form in order to be accepted and implemented. The national language policy, on which the university's policy is based, can only be inferred from various documents like the Constitution, official Gazette and other ministerial decrees (Kouega 2007) which uphold French and English as the official languages of the country. This can be seen in section 1.1.3 of the Constitution of the Republic of Cameroon (1996) which states that:

The official languages of the Republic of Cameroon shall be English and French, both languages having the same status. The state shall guarantee the promotion of bilingualism throughout the country. It shall endeavour to protect and promote national languages.

Despite this constitutional undertaking, French is clearly the dominant language of administration in Cameroon (Kouega 2002). However, Anchimbe (2011) observes that each language cluster fights for its rights and dominates in its different regions. And while there appears to be a commitment to "protect and promote" national or indigenous languages, there is no indication of how this should be done.

Given the state ideology of promoting French and English as official languages in order to promote national unity, it was therefore natural that the country's first university would also do the same and try to foster bilingualism in these two languages. The University of Yaoundé 1 uses both French and English as the MOIs and the choice of medium is left to the individual lecturers. Lecturers may summarise their lectures in the other official language (French for English speakers and English for French speakers) in order to assist students who use that language as their first official language. Tasks and assignments are given in either of the languages and students are expected to use the language in which they are most competent. 
At the same time, French and English are promoted through a compulsory course, Bilingual Training (formation bilingue), that all undergraduate students take. It can therefore be argued that the tacit language policy of this university, with its attempts to foster bilingualism, is rooted in the ideology of linguistic pluralism (Cobarrubias 1983:63-66). In addition, although the teaching and use of the indigenous languages are promoted by the Department of Linguistics and African Languages, these languages are only used for informal communication on the campus, while CPE serves as the common lingua franca. There is therefore evidence of the influence of the language hierarchy ideology (Weber and Horner 2012:16), with French and English in dominant positions, while CPE and the indigenous languages play minor roles in informal domains.

\subsubsection{The University of the Western Cape}

The South African Constitution (1996 No. 108.6) includes the following two key stipulations as part of the new democratic dispensation in South Africa, with its focus on national reconciliation and redress:

1. The official languages of the Republic are Sepedi, Sesotho, Setswana, siSwati, Tshivenda, Xitsonga, Afrikaans, English, isiNdebele, isiXhosa and isiZulu.

2. Recognising the historically diminished use and status of the indigenous languages of our people, the state must take practical and positive measures to elevate the status and advance the use of these languages.

The language policy of UWC (2003) is contained in a document formally approved by the University Council and clearly attempts to capture the spirit of these two stipulations in the Constitution. This can be seen in its aims of "ensuring equity, social development and a respect for South Africa's multilingual heritage" (Preamble of the UWC Language Policy 2003). However, English and Afrikaans are the dominant home languages of the student population, as is revealed by the following breakdown of the 2010 registration statistics (the year in which this research took place):

- English/Bilingual English and Afrikaans-speaking: 57.3\%

- isiXhosa: $24.7 \%$

- Afrikaans: $14.9 \%$

- Other SA languages: $6.3 \%$

- Foreign languages: $4.9 \%$

These statistics are clearly a factor that may diminish any urgency to do more to promote the use and development of formerly marginalised languages like isiXhosa at this university.

Given the multilingual and multicultural nature of the university, lectures are delivered in the local lingua franca, namely English, the exception being the different language departments. However, lecturers of other departments who are competent users of Afrikaans and isiXhosa are "encouraged to use the language in addition to English if it is going to ease understanding" (UWC Language Policy 2003). It should be noted that the policy contains a number of "escape clauses" like where practicable, if desired and if it is practicable to do so, that could be used to 
justify a lack of direct action to implement the policy. Students are also allowed to use the language in which they are most competent in discussions during tutorials, however they must give feedback in class in English only. Lecturers and tutors are also encouraged to use the students' first language during consultation if they are competent speakers of that language. As for assignments and tasks, students are expected to use only English apart from the departments of Afrikaans, Xhosa and other foreign languages.

Taking the historical, socio-political and demographic factors of UWC into account, it was inevitable that the writers of this policy might have been subjected to a number of conflicting ideologies. One of these ideologies is the "common sense assumption" (Tollefson 1991:11) that English should be the main MOI and medium of communication on this campus. At the same time, the policy also appeared to be informed by a number of ideological assumptions about multilingualism in South Africa held by e.g. Heugh (1995) and Alexander (1992). Although UWC's policy was written by people holding their own ideologies about the advancement of multilingualism in South Africa, the policy eventually privileged English, with Afrikaans and isiXhosa playing "supporting" roles. Therefore, ideologically, although the policy may have strived for linguistic pluralism, in practice it promotes linguistic assimilation (Cobarrubias 1983:63) and there is a very clear hierarchy of languages at this institution.

\subsection{The quantitative and qualitative findings}

In this section, the following abbreviations are used to identify the speakers quoted: FL (Francophone lecturer); AL (Anglophone lecturer); FS (Francophone student); AS (Anglophone student); EL (English home-language lecturer); AfrL (Afrikaans home-language lecturer); XS (Xhosa home-language student), and ES (English home-language student).

\subsubsection{The University of Yaoundé 1}

A comparison between the quantitative and qualitative data collected in Cameroon revealed some of the contradictions and contestations common to studies on language ideologies and attitudes. Firstly, both sets of data collected from lecturers and other stakeholders on the one hand, and students on the other, revealed that the respondents were positive towards bilingualism in French and English. Most agreed that there was a bilingual policy at the university and that both students and lecturers were supposed to be bilingual in French and English, as is evident in the following two quotes:

FL1: The University is bilingual, lecturers can teach either in French or English.

AS1: It states that French and English must be taught equally.

In addition, while a substantial majority of the students were happy to use French as MOI according to the quantitative data, the responses in the qualitative data indicated a desire for a proper implementation of a bilingual policy:

AS2: Yes, I believe so because we need to feel that bilingualism and not only mention it on papers whereas it is not practiced because French language dominates. 
According to the quantitative data, a majority (56.7\%) of the students felt that the indigenous languages did not have any role to play in their academic and future success, yet the qualitative data revealed that most felt that the use of their home language would aid comprehension of concepts as well as allow for greater identification with their culture and history:

FS2: Yes, because there is some degree of familiarity and I feel at home whenever I speak my home language, talk less of being taught in this language. I think it will be interesting to do African literature in the African languages.

Lecturers, on the other hand, were far more negative towards the use of these languages at university:

AL1: Well I think at the present state of evolution of the Cameroonian society, this cannot be envisaged for obvious reasons because most of these languages are not developed and therefore cannot be envisaged. Secondly, most of these languages in terms of coverage, i.e. geographical coverage that can be a handicap to their development and their acceptability by other members of the community.

A majority of the respondents, both lecturers and students, viewed CPE as having little value in an academic institution (despite its wide-spread use on the campus, as observed by the second author):

AS2: No, it is good at home, market, churches, to be brief, our social life. But teaching it in schools will not be appreciated because it can't help in the international community.

Thus, several complementary findings were revealed by the two sets of data from Cameroon, but the more nuanced qualitative data indicated some of the tensions underlying the responses of different respondents, particularly the Anglophones who appeared resentful at the lack of status afforded to English at this supposedly bilingual university. This resentment mirrored the perceived inequalities between Francophones and Anglophones in Cameroon:

AL2: [...] even a mere clerk in an office can make you a whole lecturer who is an Anglophone to feel bad, to feel marginalised, you know? When you say a person or a country is bilingual it means that you have the right to speak any of the languages at any given time, and the person listening has the right to understand and respond in the language he or she is comfortable in but in the ministries, when you speak your English they say "Je ne comprend pas, parle français, ici c'est Yaoundé eeh, ce n'est pas votre Bamenda, ce n'est pas Manfe ici” ['I don't understand, speak French, here it is Yaoundé eeh, it is not your Bamenda, it is not Manfe here'].

Various factors had a role to play in shaping the attitudes of the research population at this university. This included the geographical distribution of the country with $80 \%$ of the provinces being Francophone and only 20\% Anglophone. Nevertheless some Anglophones clung to an ideology that an official policy of bilingualism could create some form of equality between the two languages in Cameroon. However, as the history of the country since independence and various studies (Mbuangbaw 2000, Kouega 2003, Mforteh 2006) including this one have 
shown, this is a policy that is only partially implemented, with many "grey" areas where people simply do what is most convenient.

Ideologically, the majority of those surveyed in this study viewed the indigenous languages as inferior in comparison to the ex-colonial languages. CPE, despite its widespread use, was also severely criticised. Underlying these largely negative attitudes are the ideologies of a language hierarchy (with French, followed by English, rated as the most important languages in Cameroon) as well as the standard language ideology - the notion that languages which have been standardised enjoy a much greater prestige than other languages or varieties (Weber and Horner 2012:11-16). One major concern here was the fact that there were many indigenous languages and choosing which ones could be developed to serve as official languages or MOIs constituted a major headache for language policy makers after the country's independence in 1961 (Chumbow 1980, Kouega 2003).

\subsubsection{The University of the Western Cape}

The quantitative and qualitative data collected in South Africa revealed fewer contradictions than the data from Cameroon. Unsurprisingly, given the breakdown of home languages described above, most students and lecturers approved of the use of English as the main MOI at UWC. In addition, they believed that English has many socio-economic and political advantages associated with it as a national and an international language. Yet a small minority of the students, particularly home-language speakers of isiXhosa and Afrikaans, preferred being taught in these languages for comprehension and identity purposes, as exemplified by the following quote:

XS1: Yes, I would like to be taught in my home language, it's easier to grasp and understand.

In addition, most of the students from both sets of data supported the implementation of a multilingual policy at this university:

ES1: I am already privileged enough to have my home language being English, which is the chief MOI at my tertiary institution. I do however feel that accommodating students and using their own language makes a huge impact on their learning and would be a good idea.

Some lecturers also felt that much more could be done to implement the UWC language policy:

EL1: I think UWC could do more to make it a more multilingual environment e.g. more signage in Xhosa would be a start.

AfrL1: The policy is brilliant as it is but the issue is its implementation. It appears that the policy is only on paper but its practice is yet to come or has been completely forgotten.

Unequal power relations also emerged from the data with a considerable gap between those in authority and the subordinate students, particularly in terms of the language of power - English. In this regard, isiXhosa-L1 students complained a lot about the use of English as an MOI, 
expressing much stronger negative attitudes than other students. This was particularly apparent in the qualitative data, probably because they were able to express their views better during interviews than in the more limiting written responses. Yet despite these negative attitudes, observation as well as the comments from lecturers indicated that the students still preferred to be taught in English because of the advantages it holds:

XS2: English dominates in all aspects in SA, the TV, radio, parliament, government, notices, etc. SA is multilingual in theory because the main language here is English. We are getting to a stage where we would want to speak English even to our grandparents in the Eastern Cape forgetting that they do not understand it. Like I said earlier, English comes first before any other language and when they ask for two SA languages as a requirement for a job, I think it is just for formality as these languages are hardly ever used.

The major ideology to emerge from the UWC data was that English was the dominant language in South Africa and was unchallenged in most domains by the other official languages. Political ideology might have imposed multilingual language policies at national, provincial and university levels, but in practice these policies have had very little value.

\section{Conclusions}

While the histories and linguistic backgrounds of the University of Yaounde 1 in Cameroon and UWC in South Africa may be very different, it is indisputable that the language policies of both universities have been influenced and shaped, on the one hand, by ideologies resulting from many years of colonisation and the resulting marginalisation of the indigenous languages in both countries, and, on the other, by ideologies of nation-building and assimilation in the post-colonial era. In line with the views of Schiffman (1996) and Shohamy (2006), this paper argues that such ideologies may drive more covert policies thereby having an almost paralysing effect on attempts to implement well-intentioned, overt language policies. The paper has also shown how these ideologies find expression in particular language attitudes held by the different respondents in their responses to the questionnaires and interviews.

Another aim of this paper was to sharpen conceptual clarity between the concepts of 'language ideologies' on the one hand, and 'language attitudes' on the other (Dyers and Abongdia 2010). The study revealed that attitudes are held by individuals while ideologies find expression in societies as the overarching framework within which more personal attitudes are formed. Thus one could argue that language attitudes are often openly expressed by individuals, as can be seen from the responses quoted in this paper, while language ideologies are made visible through actual language practices which may differ quite significantly from the language policies that are created for institutions and countries. Ideologies are therefore social constructions, but attitudes relate more to the construction of people's individual and even group identities.

A few dominant and interrelated language ideologies were identified as having major influences on the language policies of both universities as well as the attempts to implement these policies. It was argued that attempts to foster bilingualism at the University of Yaoundé 1 was based on the ideology of linguistic pluralism (Cobarrubias 1983:63-66). In contrast, while the language policy of UWC may have been based on the same ideology, in practice it promoted linguistic 
assimilation (Cobarrubias 1983:63). At both universities there was also clearly a hierarchy of languages (Weber and Horner 2012:16). At the University of Yaoundé 1, the most important roles are played by French followed by English, while CPE and the indigenous languages, which are seen as inferior and underdeveloped, fulfil minor roles in informal domains. At UWC, English is indisputably regarded as the most important language, with Afrikaans and isiXhosa playing supporting roles. There was also evidence of the standard language ideology (Weber and Horner 2012:17) as the higher status accorded to standardised languages was frequently noted in the data. Some respondents held that only standardised languages should be used as MOIs, while other varieties - such as CPE in Cameroon - were negatively stigmatised. Some respondents in South Africa were even ignorant of the fact that most of the indigenous languages were standardised, probably because these languages were not being used in academic contexts. Closely linked to the standard language ideology was the ideology of linguistic purism (Weber and Horner 2012:18). This was particularly visible in the responses to the possible use of CPE in Cameroon, as well as the arguments against the use of indigenous languages at tertiary level in South Africa.

This paper has provided insight into the ways in which ideologies are shaped by the historical, socio-political and economic realities of Cameroon and South Africa respectively, as well as the lasting effects of the colonial, Western ways of seeing the world and language. Although in law South Africa has a far more progressive language policy than Cameroon, the de facto policy is one that builds on an essentialist perception of language which supports the dominant language of the state and at the same time provides international access. The ideologies that underpin the various uses of the ex-colonial and indigenous languages have a huge impact on the success or failure of implementation strategies designed to make the idealistic, explicit policies work. Despite some support for the use of indigenous languages at university and the openly expressed language loyalty of some respondents, the difficulties of promoting and using these languages in universities with highly diverse populations have also been described and acknowledged.

\section{Acknowledgement}

The authors wish to acknowledge the funding granted for this project by the Senate Research Committee of the University of the Western Cape.

\section{References}

Abongdia, J. 2013. Language ideologies in Africa: Comparative perspectives from Cameroon and South Africa. Unpublished PhD thesis. Bellville: University of the Western Cape.

Alexander, N. 1992. Language planning from below. In R. Herbert (ed.) Language and society in Africa. Johannesburg: Witwatersrand University Press. pp. 56-68.

Alidou, H. 2007. Promoting quality education in Africa: Examining the language of instruction factor. Capacity Building Workshop "Country Leadership and Implementation for Results in the EFA FTI Partnership”, 16-19 July 2007, Cape Town, South Africa. 
Anchimbe, E.A. 2011. Postcolonial linguistic voices: Stitching together identity choices and their representations. Available online: www.wikicfp.com/cfp/servlet/event.showcfp?eventid= 165\&opyownerid=26 (Accessed 15 July 2012).

Baldauf, R.B. and R.B. Kaplan. 2006. Language policy and planning in Botswana, Malawi, Mozambique and South Africa: Some common issues. In R.B. Baldauf and R.B. Kaplan (eds.) Language policy and planning in Africa, Vol. 2. Botswana, Malawi, Mozambique and South Africa. Clevedon: Multilingual Matters. pp. 5-20.

Bamgbose, A. 2000. Language and exclusion: The consequences of language policies in Africa. Münster: LIT Verlag Global.

Besemeres, M. 2006. Language and emotional experience: The voice of translingual memoir. In A. Pavlenko (ed.) Bilingual minds: Emotional experience, expression and representation. Clevedon: Multilingual Matters. pp. 34-58.

Beukes, A.-M. 2003. The first ten years of democracy: Language policy in South Africa. Paper read at the Xth Linguapax Congress on Linguistic Diversity, Sustainability and Peace, 20-23 May 2004, Barcelona, Spain.

Blackledge, A. 2005. Discourse and power in a multilingual world. Amsterdam: John Benjamins.

Cameron, D. 2001. Identity, difference and power: Locating social relations in talk. In D. Cameron (ed.) Working with spoken discourse. London: Sage. pp. 161-179.

Chumbow, S.B. 1980. Language and language policy in Cameroon. In N. Kofele-Kale (ed.) An African experiment in nation building: The bilingual republic of Cameroon since reunification. Boulder, CO: Westview Press.

Cobarrubias, J. 1983. Ethical issues in status planning. In J. Cobarrubias and J. Fishman (eds.) Progress in language planning: International perspectives. Berlin: Mouton. pp. 41-85.

Constitution of the Republic of Cameroon. 1996. Law No. 96-06 of 18 January 1996. Available online: http://www.icrc.org/ihl-nat.../Constitution\%20Cameroon\%20-\%20EN.pdf (Accessed 28 May 2012).

Constitution of the Republic of South Africa 1996. Pretoria: Government Press.

Crawford, J. 1988. Split tongue: Self-appointed guardians hide Official English's real agenda. Arizona Republic. Oct. 30. pp. C1, C3. Reprinted in J. Crawford (ed.) 1992. Language loyalties: A source book on the Official English controversy. Chicago: University of Chicago Press. pp. $171-177$.

Dewaele, J.M. 2006. Expressing anger in multiple languages. In A. Pavlenko (ed.) Bilingual minds: Emotional experience, expression and representation. Clevedon: Multilingual Matters. pp. 118-151. 
Dyers, C. and J. Abongdia. 2010. An exploration of the relationship between language attitudes and ideologies in a study of Francophone learners of English in Cameroon. Journal of Multilingual and Multicultural Development 31(2): 119-134.

Echu, G. 1999. Colonialism and linguistic dilemma in Africa: Cameroon as a paradigm (revisited). Quest XIII(1-2): 19-26.

Echu, G. 2003. Coping with multilingualism: Trends in evolution of language policy in Cameroon. Available online: http://web.fu-berlin.de/phin/phin25/p25t2.htm (Accessed 7 September 2007).

Echu, G. 2004. The language question in Cameroon. Available online: http://www.linguistikonline.de/18_04/Echuhtml (Accessed 20 May 2007).

Fairclough, N. 2003. Analysing discourse: Textual analysis for social research. New York: Routledge.

Fonlon, B. 1969. The language problem in Cameroon: An historical perspective. ABBIA 22: 5-40.

Free Online Dictionary. Available online: http://www.thefreedictionary.com/ideology (Accessed 15 February 2014).

Heugh, K. 1995. From unequal education to the real thing. In K. Heugh, A. Siegruhn and P. Plüddemann (eds.) Multilingual education for South Africa. Johannesburg: Heinemann. pp. 42-52.

Heugh, K. 2003. Language policy and democracy in South Africa. The prospects of equality within rights-based policy and planning. PhD thesis. Stockholm: Centre for Research on Bilingualism, Stockholm University.

Hill, L. 2010. Language and status: On the limits of language planning. Stellenbosch Papers in Linguistics 39: 41-58.

Hseih, H.F. and S.E. Shannon. 2005. Three approaches to qualitative content analysis. Qualitative Health Research 15(9): 1277-1288.

Irvine, J. 1989. When talk isn't cheap: Language and political economy. American Ethnologist 16(2): 248-267.

Irvine, J.T. and S. Gal. 2000. Language ideology and linguistic differentiation. In P. Kroskrity (ed.) Regimes of language: Ideologies, polities and identities. Santa Fe and Oxford: School of American Research Press. pp. 35-84.

Kaschula, R. and C. Anthonissen. 1995. Communicating across cultures in South Africa: Towards a critical language awareness. Johannesburg: Witwatersrand University Press.

Kouega, J.-P. 2002. English in Francophone elementary grades in Cameroon. Language and Education 17(6): 408-419. 
Kouega, J.-P. 2003. Influence of contacts between Western and African cultures on English in Cameroon. Berlin: Glottolog Langdoc.

Kouega, J.-P. 2007. The language situation in Cameroon. Current Issues in Language Planning 8(1): 3-94.

Kroskrity, P. 2000. Language ideological perspectives. In P. Kroskrity (ed.) Regimes of language: Ideologies, polities and identities. Santa Fe and Oxford: School of American Research Press. pp. 1-34.

Likert, R. 1932. A technique for the measurement of attitudes. Archives of Psychology 22(140): $5-55$.

Mbuagbaw, T.E. 2000. Language and education in Cameroon: A sociolinguistic perspective. African Journal of Applied Linguistics (AJAL) 1: 135-145.

Mforteh, S.A. 2006. Cultural innovations in Cameroon's linguistic tower of Babel. TRANS. Internet-zeitschrift für kulturwissenschaften. No.16/2005. Available online: http://www.inst.at/ trans/16Nr/03_2/mforteh16/htm (Accessed 25 March 2009).

Myers-Scotton, C. 2006. Multiple voices: An introduction to bilingualism. Oxford: Blackwell Publishing.

Neethling, B. 2010. Xhosa as medium of instruction in higher education: Pie in the sky? Per Linguam 26(1): 61-73.

Nkwi, P.N. and A. Socpa. 2007. Anthropology at the University of Yaoundé I: A historical overview, 1962-2008. The African Anthropologist 14(1-2): 65-88.

Pavlenko, A. 2004. The making of an American: Negotiation of identity at the turn of the twentieth century. In A. Pavlenko and A. Blackledge (eds.) Negotiation of identities in multilingual contexts. Clevedon: Multilingual Matters. pp. 34-67.

Roberge, P.T. 1995. The formation of Afrikaans. In R. Mesthrie (ed.) Language and social history: Studies in South African sociolinguistics. Claremont, South Africa: David Phillips Publishers. pp. 68-88.

Schiffman, H. 1996. Linguistic culture and language policy. London: Routledge.

Shohamy, E. 2006. Language policy: Hidden agendas and new approaches. Oxford: Routledge.

Skuttnab-Kangas, T. 2000. Linguistic genocide in education - or worldwide diversity and human rights? New York: Lawrence Erlbaum Associates.

Spolsky, B and E. Shohamy. 2000. Language practice, language ideology and language policy. In R.D. Lambert and E. Shohamy (eds.) Language policy and pedagogy. Philadephia, PA: John Benjamins. pp. 1-42. 
Tamanji, P. 2008. A success story in official bilingualism: Lessons for a mother-tongue based multilingual educational programme in Cameroon. Revue Internationale des Arts, Lettres et Sciences Sociales 1(2): 151-172.

Tollefson, J. 1991. Planning language, planning inequality: Language policy in the community. London and New York: Longman.

University of the Western Cape 2003. University of Western Cape (UWC): Language policy. Available online: www.uwc.ac.za/Documents/Language_Policy_C2003-3.pdf (Accessed 17 February 2011).

Weber, J. and K. Horner. 2012. Introducing multilingualism: A social approach. London: Routledge.

Wodak, R. 2001. What CDA is about - A summary of its history, important concepts and its developments. In R. Wodak and M. Meyer (eds.) Methods of Critical Discourse Analysis. London: Sage. pp. 1-13. 